J. Dairy Sci. 96:4323-4332

http://dx.doi.org/10.3168/jds.2012-6266

(C) American Dairy Science Association ${ }^{\circledR}, 2013$.

\title{
The responsiveness of subclinical endometritis to a nonsteroidal antiinflammatory drug in pasture-grazed dairy cows
}

\author{
N. V. Priest, ${ }^{\star} \dagger^{1}$ S. McDougall, $\ddagger$ C. R. Burke, ${ }^{*}$ J. R. Roche, ${ }^{*}$ M. Mitchell,§\# K. L. McLeod, ${ }^{*}$ S. L. Greenwood, $\dagger \|$ \\ and S. Meier* \\ *DairyNZ Limited, Hamilton 3240, New Zealand \\ †Faculty of Agriculture and Life Sciences, Lincoln University, Lincoln 7647, New Zealand \\ $\ddagger$ Cognosco, Animal Health Centre, Morrinsville 3300, New Zealand \\ §Liggins Institute, University of Auckland, Auckland 1142, New Zealand \\ \#University of Queensland Centre for Clinical Research, Brisbane, St. Lucia, Queensland 4072, Australia \\ IIDepartment of Animal Science, University of Vermont, Burlington 05405
}

\section{ABSTRACT}

The objective of this study was to determine if the inflammation associated with subclinical endometritis (SCE) is a part of the mechanism by which reproductive performance is reduced in cows with this disease. If it is, reducing inflammation associated with SCE with a nonsteroidal antiinflammatory drug (NSAID) should reduce the severity [as measured by average polymorphonuclear cell (PMN) percentage] of uterine pathology and improve reproductive performance. It was also investigated whether the NSAID treatment reduced metabolic indicators of systemic inflammation previously reported to be altered in cows with SCE. Holstein-Friesian and Friesian-Jersey cross dairy cows $(\mathrm{n}=213)$ were paired by calving date and $\mathrm{d}-14$ uterine PMN percentage and randomly assigned to 3 injections at intervals of $3 \mathrm{~d}$ of an NSAID (1.4 $\mathrm{mg}$ of carprofen/ $\mathrm{kg} ; \mathrm{n}=104$ ) between 21 and $31 \mathrm{~d}$ postpartum or left as untreated controls $(\mathrm{n}=109)$. Cows with $\geq 14 \%$ PMN (upper quartile of PMN percentage) in the cytological sample collected at d 14 postpartum were defined as having SCE. The average d-14 PMN percentage was low $(9.9 \%)$ and a high self-cure rate of SCE $(>90 \%)$ at d 42 was observed. Treatment with an NSAID reduced plasma concentrations of aspartate aminotransferase and increased pregnancy rate in SCE cows. However, no effect of the NSAID treatment was observed on PMN percentage at d 42 , postpartum anovulatory interval, or milk production. Compared with cows without SCE, cows with SCE had lower plasma albumin concentration, albumin:globulin ratio, and body condition score, but higher nonesterified fatty acids on the day of calving. These results indicate that cows with SCE are experiencing a physiological dysfunction, including

Received October 14, 2012.

Accepted March 15, 2013.

${ }^{1}$ Corresponding author: nicola.priest@dairynz.co.nz lower body condition, liver dysfunction, and greater metabolic challenge during the periparturient period. Further research is required to determine the effect of NSAID on SCE and to evaluate the influence of timing of drug application on treatment effectiveness.

Key words: dairy cow, subclinical endometritis, antiinflammatory, carprofen

\section{INTRODUCTION}

Seasonal, pasture-based dairy cows are constrained to a 365-d intercalving interval, leaving $83 \mathrm{~d}$ from calving to reestablish pregnancy (Rhodes et al., 2003). A rapid restoration of the uterus to a reproductively capable state after calving is, therefore, critical. Uterine disease, such as subclinical endometritis, impedes uterine recovery. Subclinical endometritis (SCE) is a uterine disorder characterized by an increased proportion of polymorphonuclear cells (PMN) in the uterus after calving (Barlund et al., 2008; Sheldon et al., 2009; Dubuc et al., 2010). Subclinical endometritis has been reported to be a significant problem in both pasture-based and TMRbased dairy systems, with incidence ranging from 6 to 53\% (Gilbert et al., 2005; Green et al., 2009). Negative effects of SCE on reproductive performance include a longer postpartum anovulatory interval (PPAI), lower first-service conception rate and overall pregnancy rate, and more services per conception (Gilbert et al., 2005; Barlund et al., 2008; Burke et al., 2010); lower milk production and altered milk composition have also been reported (Green et al., 2009; Burke et al., 2010; McDougall et al., 2011).

The cause of SCE and mechanistic links to reduced fertility are not well understood. Subclinical endometritis may result from bacterial infection, with LPS disruption of the hypothalamic-ovarian axis and uterine secretions reducing reproductive performance (Battaglia et al., 1999; Herath et al., 2007). Recent indications, however, are that PMN percentage-defined 
SCE in pasture-grazed dairy cows is associated with liver dysfunction and systemic inflammation, and that it is the inflammation (as assessed by PMN percentage) associated with endometritis and not necessarily the presence of bacteria in the uterus that causes the negative effect on reproductive performance (Green et al., 2009; Burke et al., 2010; McDougall et al., 2011). A stronger association between poor reproductive performance and inflammation in SCE cows, rather than bacteria, was also reported by Barański et al. (2012) in a TMR-based system. Indicators of liver dysfunction and systemic inflammation reported for SCE cows include a lower albumin:globulin ratio and elevated plasma concentrations of aspartate aminotransferase (ASAT) and glutamate dehydrogenase (GDH; Bertoni et al., 2008; Burke et al., 2010). This association of SCE with inflammation (both systemic and uterine), rather than uterine bacteria, indicates that treatment of SCE may need to focus on reducing inflammation rather than eliminating uterine bacteria, a case for the use of a nonsteroidal antiinflammatory drug (NSAID). This is supported by the lack of a consistent beneficial treatment effect of antibiotics (Kasimanickam et al., 2005; Galvão et al., 2009b) and prostaglandins (Kasimanickam et al., 2005; Galvão et al., 2009a).

To test the role of local (and systemic) inflammation associated with SCE in reducing reproductive performance, an NSAID was used in this study. One pathway through which NSAID reduces inflammation is the cyclooxygenase enzyme-prostaglandin pathway. The NSAID inhibits the action of cyclooxygenase and prevents the secretion of prostaglandin, a proinflammatory molecule (Sordillo et al., 2009; Erdem and Guzeloglu, 2010; Heuwieser et al., 2011). The timing of NSAID treatment is an important consideration, however, because prostaglandin-mediated inflammation is a normal part of the uterine involution process after calving (Barlund et al., 2008). For this reason, NSAID treatment was delayed until $21 \mathrm{~d}$ postpartum in the current study.

It was hypothesized that treatment with NSAID between 21 and 31 DIM would reduce the severity (average PMN percentage) of uterine pathology at $42 \mathrm{~d}$ postpartum without lengthening the PPAI and would mitigate the negative association of SCE on reproduction and milk production by reducing inflammation and improving liver function. Additionally, the effect of the NSAID treatment on circulating metabolites and minerals previously reported to be altered in cows with $\mathrm{SCE}$ was investigated. The objectives of this study were to determine the effect of an NSAID on PMN percentage and associated effects on reproduction, metabolic indicators, and milk production.

\section{MATERIALS AND METHODS}

\section{Experimental Design}

Multiparous cows ( $\mathrm{n}=213 ; 136$ Holstein-Friesian and 77 Holstein-Friesian $\times$ Jersey) aged $5.4 \pm 2.2$ yr $( \pm$ SD $)$ and with a mean BW of $445 \pm 56.3 \mathrm{~kg}$ were enrolled at Scott Farm (DairyNZ, Hamilton, New Zealand; $37^{\circ} 47^{\prime} \mathrm{S}$, $175^{\circ} 19^{\prime} \mathrm{E}$ ) between May and October 2011. Primiparous cows were not included due to a lack of availability at the research farm. The number of cows required for the NSAID and control groups $(\mathrm{n}=100)$ to detect ( $80 \%$ power, $5 \%$ significance) a one-third reduction in PMN percentage (e.g., a reduction from 15 to $10 \%$ PMN) from d 14 to 42 cytology was calculated using a standard deviation of 0.45 ( $\log _{10}$ of PMN percentage; S. Meier, unpublished data) and a detectable difference of 0.18 (difference between the d 14 and $42 \log _{10}$ PMN percentage counts). Prior approval for animal use was obtained from the Ruakura Animal Ethics Committee (Hamilton, New Zealand; no. 12294).

To ensure that the control and NSAID treatment groups were balanced for PMN percentage, a uterine cytology sample was taken on d 14 to 17 postpartum (d-14 PMN percentage). Cows were blocked on calving date and d-14 PMN percentage before being randomly allocated to either the control $(\mathrm{n}=109)$ or the NSAID $(\mathrm{n}=104)$ treatment group. To allow time for involution to proceed unimpeded, the NSAID treatment was initiated at 21 to $25 \mathrm{~d}$ postpartum. The cows in the NSAID treatment group (Carprieve LA; Norbrook New Zealand Ltd., Auckland, New Zealand; $50 \mathrm{mg}$ of carprofen $/ \mathrm{mL}$ ) were given 3 injections (each injection = $1.4 \mathrm{mg}$ of carprofen $/ \mathrm{kg}$ of BW; $1 \mathrm{~mL}$ of carprofen $/ 35 \mathrm{~kg}$ of BW) at intervals of $3 \mathrm{~d}$, between 21 and $31 \mathrm{~d}$ postpartum. The rationale for this treatment regimen was to ensure an extended period of coverage, as carprofen has a plasma elimination half-life of 45 to $70 \mathrm{~h}$ (Ludwig et al., 1989; Norbrook Laboratories, 2011).

All cows were examined using the Metricheck procedure (McDougall et al., 2007) at d 14 and 42. A Metricheck score of $\geq 3$ was determined in 22 cows at d 14 and in 4 cows at d 42 . None of these cows received antibiotic treatment and all were included in the analyses. Cows with calving difficulty $(\mathrm{n}=1)$, retained fetal membranes $(\mathrm{n}=4)$, or milk fever $(\mathrm{n}=12)$ were included. Cows $(\mathrm{n}=2)$ were excluded if they received a systemic antibiotic during the experiment.

\section{Uterine Cytology}

Uterine endometrial cytology samples were collected on d 14 to 17 (d-14 PMN percentage) and d 42 to 45 (d42 PMN percentage) postpartum as described by Burke 
et al. (2010). The vulva of the cow was cleaned with a paper towel and then a double-guarded, modified, AI pipette was passed through the cervix and into the uterus. A clean stylet with a clean cytology brush attached (Pap endocervical sample brush; EBOS Group Ltd., Christchurch, New Zealand) was used to collect a sample from the uterine wall. The stylet was then retracted into the AI sheath and all sampling equipment removed from the cow. Material recovered was rolled onto a microscope slide and air dried. The slides were stained once completely dry (Diff-Quick; Dade Behring Inc., Newark, DE). The slides were examined by a veterinary pathologist [Institute of Veterinary, Animal and Biomedical Sciences (IVABS), Massey University, Palmerston North, New Zealand] for determination of the proportion of PMN present. Areas of each slide that contained small clusters of epithelial cells (5 to 20 per cluster) were preferentially selected and all identifiable nucleated cells counted. Based on d-14 PMN percentage results, cows were retrospectively grouped into quartiles and cows in the upper quartile $(\geq 14 \%$ PMN, high-PMN group) were classified as having SCE. Subclinical endometritis at d 42 was defined as PMN of $\geq 7 \%$, based on the results reported by Burke et al. (2010). Cure of SCE from d 14 to 42 was defined as a cow that had $\geq 14 \%$ PMN at d 14 but that had $<7 \%$ PMN at $\mathrm{d} 42$. The $<7 \%$ PMN cutoff was based on Dubuc et al. (2010) reporting that a PMN percentage of $<7$ at 32 to 38 postpartum did not have a negative effect on reproductive outcomes.

\section{Postpartum Anovulatory Interval}

Progesterone was measured in plasma collected weekly from 3 to $54 \mathrm{~d}$ postpartum using a commercial kit (progesterone Coat-A-Count; Siemens, Los Angeles, $\mathrm{CA}$ ). The average intraassay coefficient of variation for the high control was $8.4 \%$ and $14.6 \%$ for the low control, and the minimum detectable level was 0.08 $\mathrm{ng} / \mathrm{mL}$. The average interassay coefficient of variation was $0.5 \%$ for the high control and $9.3 \%$ for the low control. Progesterone data were used to determine the PPAI, which was defined as the interval from calving to the first sample day that the plasma progesterone concentration was $\geq 1 \mathrm{ng} / \mathrm{mL}$. The PPAI for 43 of 108 control cows and 32 of 103 NSAID cows was $>54 \mathrm{~d}$, as their progesterone concentrations remained $<1 \mathrm{ng} / \mathrm{mL}$ throughout the sampling period.

\section{Breeding Management}

The seasonal breeding period was $10 \mathrm{wk}$, from September 20 to November 29. The number of days since conception was estimated by a veterinarian at the final pregnancy test (January 12, 2012). This was matched with breeding records. For 4 cows, days pregnant were not consistent with the breeding records; therefore, the estimated days pregnant from the veterinarian was used instead of the days pregnant from the breeding records.

\section{Blood Sample Collection}

Duplicate venous blood samples were collected weekly from the tail head into 2 evacuated blood tubes containing sodium heparin or $\mathrm{K}_{2} \mathrm{EDTA}$ as the anticoagulant (Vacutainer; Becton Dickinson, and Co., Franklin Lakes, NJ) for every cow from $28 \mathrm{~d}$ before the estimated calving date to 46 to $54 \mathrm{~d}$ after calving. Additional samples were collected on the day of calving (d 0) and $4 \mathrm{~d}$ postpartum (d 4). Blood samples were collected at the same time each day relative to milking (before a. m. milking for weekly samples and before $\mathrm{p}$. $\mathrm{m}$. milking for $\mathrm{d} 0$ and 4 samples). After centrifugation at $1,835 \times g$ for 15 min at $4^{\circ} \mathrm{C}$, duplicate plasma samples were collected and stored at $-20^{\circ} \mathrm{C}$.

Plasma was submitted to Gribbles Veterinary Pathology Ltd. (Hamilton, New Zealand) within $40 \mathrm{~d}$ of sampling. All assays were colorimetric and performed at $37^{\circ} \mathrm{C}$ with a Roche Modular P800 analyzer (Roche Diagnostics Corp., Indianapolis, IN), using Roche Modular commercial kits. All samples were analyzed for albu$\min (\mathrm{g} / \mathrm{L}$; bromocresol green reaction at $\mathrm{pH} 4.1)$, total protein $(\mathrm{g} / \mathrm{L}$; biuret reaction method), ASAT (IU/L; catalyzing activity of transamination of L-aspartate to oxaloacetate), GDH (IU/L; catalyzing activity of NADH-dependent conversion of $\alpha$-ketoglutarate to glutamate), NEFA (mmol/L; commercial kit using the acyl CoA synthase, acyl-CoA oxidase method; Wako, Osaka, Japan), and $\mathrm{Mg}$ (mmol/L; xylidyl blue reaction). Day0 and -4 samples were also analyzed for $\mathrm{Ca}(\mathrm{mmol} / \mathrm{L}$; $o$-cresolphthalein complexone method) concentrations. The interassay and intraassay coefficients of variation for all assays were $<5$ and $<2 \%$, respectively. Levels of Se $(\mathrm{nmol} / \mathrm{L}), \mathrm{Zn}(\mu \mathrm{mol} / \mathrm{L})$, urea $(\mathrm{mmol} / \mathrm{L})$, and $\gamma$-glutamyl transferase (IU/L) were determined by Gribbles Veterinary Pathology Ltd. in plasma from additional blood samples collected from 20 randomly selected cows at 2 to 3 wk pre- and postpartum as a measure of herd-level status for these minerals and metabolites.

\section{Milk Production}

Individual milk yields ( $\mathrm{kg} / \mathrm{cow}$ per day) were recorded twice daily (Alpro; DeLaval, Tumba, Sweden). Milk protein, fat, and lactose yields were determined weekly (FT120; Foss Electric A/S, Hillerød, Denmark), and SCC every second week (Fossomatic; Foss Electric A/S), by Fourier-transfer infrared spectroscopy. 


\section{Grazing Management and Body Condition Scoring}

Cows were maintained as 2 separate herds: a dry (precalving) and a milking herd, until all cows calved. Both herds received a generous allowance of fresh pasture (ryegrass-white clover mix) supplemented with maize silage and grass silage. Cow BCS (10-point scale; Roche et al., 2004) was assessed every second week until June 1 and then weekly until the end of the experiment.

\section{Statistical Analysis}

Polymorphonuclear Cell Percentage. The d 14 and 42 PMN percentages were analyzed using linear models. The d-14 PMN percentage was initially included as a covariate for d- $42 \mathrm{PMN}$ percentage, but was excluded when not significant. Angular transformation of PMN percentage was performed before analysis, but the raw means are presented to aid interpretation.

Associations between PMN percentage and the variables measured in this study were analyzed using 3 PMN percentage groups calculated from d-14 PMN percentage results: high (upper 25\%; $\mathrm{n}=53 ; \mathrm{PMN}$ $\geq 14 \%$ ), medium (middle $50 \% ; \mathrm{n}=105$; PMN 2 to $13 \%$ ), and low (lower $25 \%$; $=53$; PMN $\leq 1 \%$ ).

Reproductive Measures. The proportion of cows that ovulated by a specified date postpartum was analyzed using generalized linear models with a binomial error distribution in GenStat 14 software (VSN International Ltd., 2011). Breed (Holstein-Friesian vs. Holstein-Friesian cross), age ( 3 yr old vs. $\geq 4$ yr old), their interaction, and PMN group (described above) were included in the model as fixed effects. When estimating the effect of NSAID treatment, treatment and the interaction of the PMN groups with treatment were also included as fixed effects. Cow was included as a random effect. Metricheck group (score $\leq 2$ vs. $\geq 3$ ) was initially included in the model, but excluded when not significant. The PPAI was analyzed using a proportional hazards regression to allow for censored data resulting from having only a lower bound for PPAI for cows still anovular at the end of the measurement period. For the effect of NSAID treatment, cows that had ovulated before treatment were excluded from the analyses $(\mathrm{n}=20)$.

Pregnancy status was determined by the presence or absence of a viable fetus using transrectal ultrasonography at the final pregnancy testing on January 12, 2012. Conception dates were assigned to the corresponding insemination date for the AI-bred cows. For the naturally mated cows, the fetal age was used to calculate conception date. Conception dates were used to calculate the proportion pregnant by 6 ( 6 -wk in-calf rate) and $10 \mathrm{wk}$ (10-wk in-calf rate) after the planned start of mating (start of the seasonal breeding period). Those diagnosed as nonpregnant by 10 wk were used to calculate the nonpregnancy rate. The 3 -wk submission rate and conception rate were not calculated, as half of the cows were naturally mated for the full 10 wk of the mating period. The association between d- 42 PMN percentage and pregnancy status was not investigated, as only 12 of 213 (8 control and 4 NSAID) cows had SCE (PMN percentage $\geq 7 \%$ ) by $d 42$. Pregnancy rates were analyzed using generalized linear models with a binomial error distribution. The model included breed (Holstein-Friesian vs. Holstein-Friesian cross), age (3 yr old vs. $\geq 4$ yr old), their interaction, PMN group (described above), and mating (AI vs. natural) as fixed effects. When estimating the effect of NSAID treatment, treatment and the interaction of the PMN groups with treatment were also included as fixed effects. Cow was included as a random effect. Metricheck group (score $\leq 2$ vs. $\geq 3$ ) was initially included in the model, but excluded when not significant.

Metabolites, Milk Production, and BCS. The metabolites, milk production, and BCS data were analyzed using mixed models. The metabolite data were divided into 5 periods: precalving period $(-28$ to -1 d postpartum), d 0, d 4, pretreatment (6 to $19 \mathrm{~d}$ postpartum), and treatment (20 to $47 \mathrm{~d}$ postpartum). The BCS data were divided into 3 periods: precalving period ( -28 to $-1 \mathrm{~d}$ postpartum), pretreatment (6 to 19 d postpartum), and treatment (20 to $47 \mathrm{~d}$ postpartum). The milk production data were divided into 2 periods: pretreatment ( 1 to $21 \mathrm{~d}$ postpartum) and treatment (3 wk from $4 \mathrm{~d}$ after the start of treatment). Metabolite (ASAT, GDH, and NEFA) and SCC data were $\log _{10}$ transformed before analysis, but the raw means are presented to aid interpretation. The model for the precalving and pretreatment period analyses included breed (Holstein-Friesian vs. Holstein-Friesian cross), age (3 yr old vs. $\geq 4$ yr old), their interaction, and PMN group (described above) as fixed effects. For the treatment period model, treatment and the interaction of the PMN groups with treatment were also included as fixed effects. Cow was included as a random effect. When estimating the effect of NSAID treatment, a covariate was also included in the model, as pretreatment data may be associated with PMN group. The covariate period for the metabolite and BCS data was the pretreatment data. For the milk data, the covariate period was the week before treatment. To estimate the interaction between PMN group with NSAID treatment, without the confounding of PMN group and pretreatment data, the covariate for each variable was calculated by using the residuals from a linear model, with the pretreatment data as stated above as the dependent variable and age, breed, PMN group, and interactions as the fixed effects. 
No covariate was included in analyses when estimating PMN group differences for the treatment period.

Alternative models using PMN percentage as a continuous variable in place of the categorical PMN group were also tested. These alternative models did not alter any of the statistical outcomes or interpretations, and the results from these are not presented. For all analyses, a significant effect was declared at $P<0.05$ and a trend at $P<0.1$.

\section{RESULTS}

Average d-14 and -42 PMN percentages were 9.9 and $1.5 \%$, respectively (Figure 1), with no effect of NSAID treatment on d-42 PMN percentage [1.4 and $1.7 \%$ for the control and NSAID groups, respectively; standard error of the difference $($ SED) $=0.5]$. The SCE cure rate for the control and NSAID group was 92.3 and $96.3 \%$, respectively.

\section{Reproduction}

The NSAID treatment did not affect postpartum ovulation rates ( 46 and $56 \%$ ovulated by d 45 postpartum for the control and NSAID groups, respectively; $P$ $>0.15)$, and no interactions $(P=0.98)$ were observed between treatment and PMN group. A trend $(P=0.09)$ was found for the low-PMN group to have a higher proportion of cows ovulated by $28 \mathrm{~d}$ postpartum than the medium- or high-PMN groups, but not at other times (Figure 2).

Pregnancy rates were not different between the control and NSAID treatment groups $(P>0.28)$; however, an interaction $(P=0.04)$ was observed between NSAID treatment and PMN group 4 wk after the planned start of mating and a trend for an interaction existed at wk 5 $(P=0.06), 8(P=0.07), 9$ and $10(P=0.09$; Figure 3$)$. The interaction reflects an increase in pregnancy rate in the high-PMN group treated with NSAID, but not the low- or medium-PMN groups. No associations were determined between PMN category and pregnancy rates $(P>0.24)$. The 6 -wk in-calf rate was 63 and $70 \%$ for the control and NSAID groups, respectively $(P=0.32)$. The nonpregnancy rate after $10 \mathrm{wk}$ of mating was not affected by treatment: $18 \%$ for the control group and $20 \%$ for the NSAID group $(P=0.72)$.

\section{Metabolites}

Following treatment with NSAID, cows had lower plasma concentration of ASAT $(P=0.04)$ and GDH $(P=0.18)$ than untreated cows. The NSAID treatment did not affect the plasma concentrations of the other metabolites measured $(P>0.27)$. No interaction was a) d 14 PMN \%

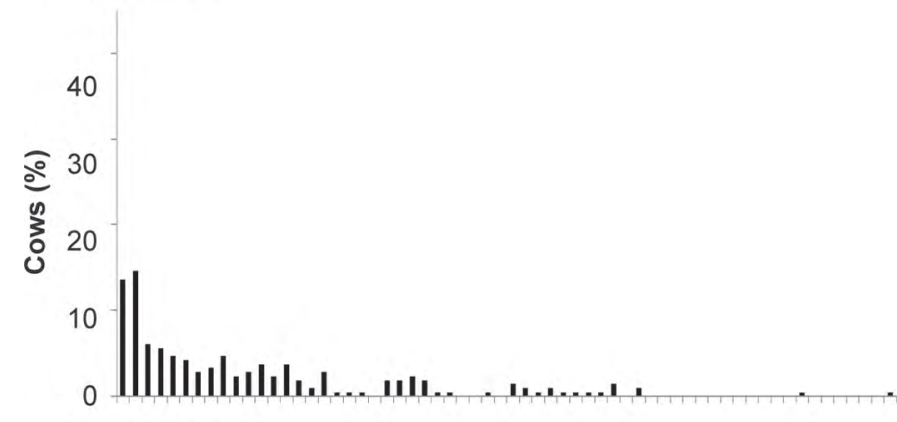

b) d 42 PMN \%

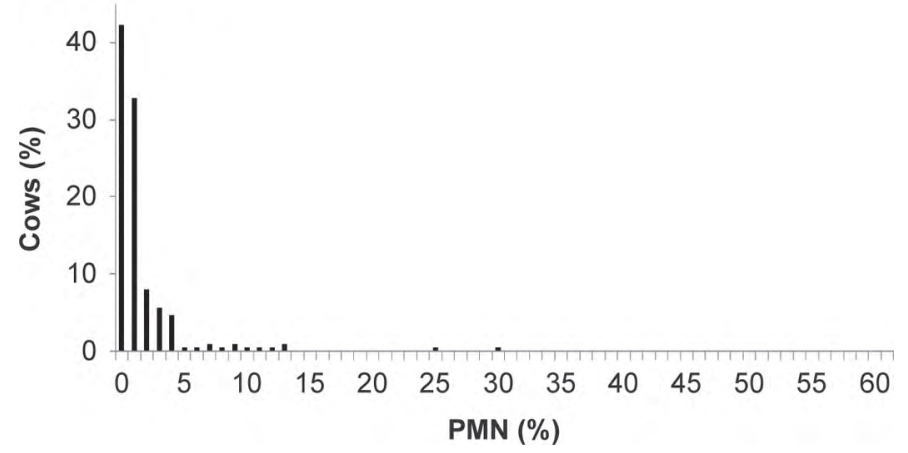

Figure 1. Polymorphonuclear cell (PMN) percentage distribution in uterine cytology samples from dairy cows at (a) d 14 and (b) d 42 postpartum.

determined between PMN group and treatment for the metabolic measures.

Plasma albumin concentrations declined pre- $(P=$ $0.08)$ and postpartum $(P<0.001)$ and plasma NEFA increased $(P=0.03)$ on the day of calving with increasing PMN percentage (Figures 4 and 5). The albumin:globulin ratio tended $(P=0.07)$ to be lower in the high-PMN group before the NSAID treatment. Prevalence of SCE was associated with indicators of liver function, with high-PMN cows tending $(P>$ 0.12 ) toward greater ASAT and GDH concentrations in blood than low-PMN cows pre- and postpartum. No associations were determined between PMN group and plasma concentrations of total protein and $\mathrm{Mg}$ at any time point, but plasma calcium concentration tended to be $(P=0.09)$ lower in the high-PMN group on the day of calving.

\section{Milk Production and BCS}

The mean milk production and composition values for the first $6 \mathrm{wk}$ of lactation were as follows: milk yield $=18.9 \mathrm{~kg} / \mathrm{d}$, milk fat $=0.86 \mathrm{~kg} / \mathrm{d}$, milk protein $=0.66 \mathrm{~kg} / \mathrm{d}$, lactose $=0.93 \mathrm{~kg} / \mathrm{d}$, and $\mathrm{SCC}=66,100$ cells $/ \mathrm{mL}$. The NSAID treatment did not affect $(P>$ 
$0.74)$ any of the milk production variables measured, nor was there an effect on BCS $(P=0.54$, NSAID $=$ 4.1 , control $=4.1, \mathrm{SED}=0.03)$. No associations were determined between PMN category and any of the milk composition variables measured. No difference $(P=$ 0.18 ; SED $=0.52$ ) existed in milk yield between the low- $(18.9 \mathrm{~kg} / \mathrm{d})$ and high-PMN groups $(18.0 \mathrm{~kg} / \mathrm{d})$. The high-PMN group was thinner (0.2 BCS units) than both the medium- and low-PMN groups pre- $(P=0.09$; $4.6,4.8$, and 4.8 , respectively) and postpartum $(P<$ $0.05 ; 4.0,4.2$, and 4.2 , respectively). No interactions were detected between PMN group and NSAID treatment for BCS. A tendency $(P=0.08)$ existed for an interaction between PMN group and treatment for milk fat, with milk fat decreasing from the low- to highPMN groups in the NSAID-treated cows $(0.87,0.83$, and $0.82 \mathrm{~kg} / \mathrm{d}$ for the low-, medium-, and high-PMN groups, respectively).

\section{DISCUSSION}

The objective of this study was to determine if reducing inflammation associated with SCE through treatment with an NSAID would reduce the severity (average PMN percentage) of uterine disease at $42 \mathrm{~d}$ postpartum, improve reproductive performance, and increase milk production in cows with SCE. In spite of a lower-than-expected average d-14 PMN percentage (9.9\% PMN on d 14 postpartum), coupled with a $90 \%$ self-cure rate by d 42 postpartum, some beneficial effects of NSAID were observed on indicators of health and reproductive performance of dairy cows in a pasture-grazed, seasonal system.

\section{Effect of NSAID on Reproduction, Metabolic Indicators, and Milk Production}

An interaction was detected between PMN percentage and NSAID treatment for pregnancy rate 4 to 10 wk after onset of breeding, indicating a beneficial effect of treatment on pregnancy rate in the high-PMN cows. In addition, treatment with an NSAID appeared to improve liver function, with reductions in plasma ASAT and GDH concentrations relative to untreated cows; this indicates that the NSAID treatment had some of the intended antiinflammatory effect. These results confirm the efficacy of treatment with NSAID in moderately improving liver function in all NSAID-treated cows and pregnancy rate in high-PMN cows. Data also indicated that NSAID treatment had no negative effect on these parameters in low-PMN cows.

However, no effect of NSAID treatment was observed on d-42 PMN percentage, the proportion of cows ovulated by a specified date, PPAI, or milk production.

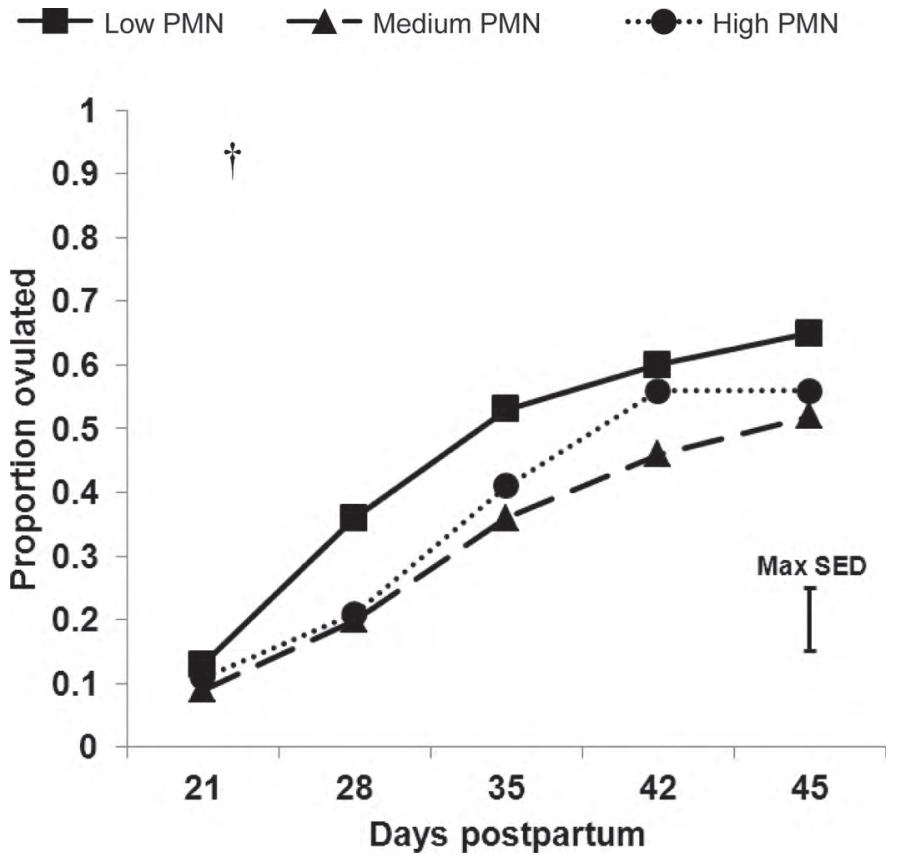

Figure 2. Association between polymorphonuclear cell (PMN) group and the proportion of cows ovulated by a specified day postpartum. The PMN groups are based on uterine cytology results from samples collected on d 14 postpartum: low PMN ( $\leq 1 \%$ PMN), medium PMN (2 to $13 \%$ PMN), and high PMN ( $\geq 14 \%$ PMN). Ovulation was defined as the first sample day postpartum that progesterone concentration was $>1 \mathrm{ng} / \mathrm{mL}$. Raw means and the maximum standard error of the difference (Max SED) are presented. $\dagger$ A trend $(P=0.09)$ existed for the low-PMN group to have a higher proportion of cows ovulated by 28 d postpartum than the medium- or high-PMN groups, but not at other times.

The reason for the lack of treatment effect on these variables is not clear. One possible explanation is the lower-than-expected d-14 PMN percentage (average of $9.9 \%$ ) among the experimental animals, coupled with a high $(>90 \%)$ self-cure rate among cows defined as having SCE at d 14. This outcome potentially resulted in a lack of statistical power to detect a treatment response. Alternatively, sufficient concentrations of carprofen, to effect a beneficial reduction of uterine inflammation, may not have reached the uterine tissues due to the route of drug administration used (subcutaneous); a more direct method of administration, such as intrauterine application, may produce a different result to that observed in the current study.

Another potential reason for the lack of treatment may have been because initiation of treatment was delayed until $21 \mathrm{~d}$ postpartum to avoid the risk of impeding the prostaglandin-mediated process of uterine involution. However, as the metabolite results indicated that SCE cows were experiencing a degree of liver dysfunction even before calving, delaying treatment to $21 \mathrm{~d}$ postpartum may have reduced the potential benefit of treatment on reproduction and milk produc- 


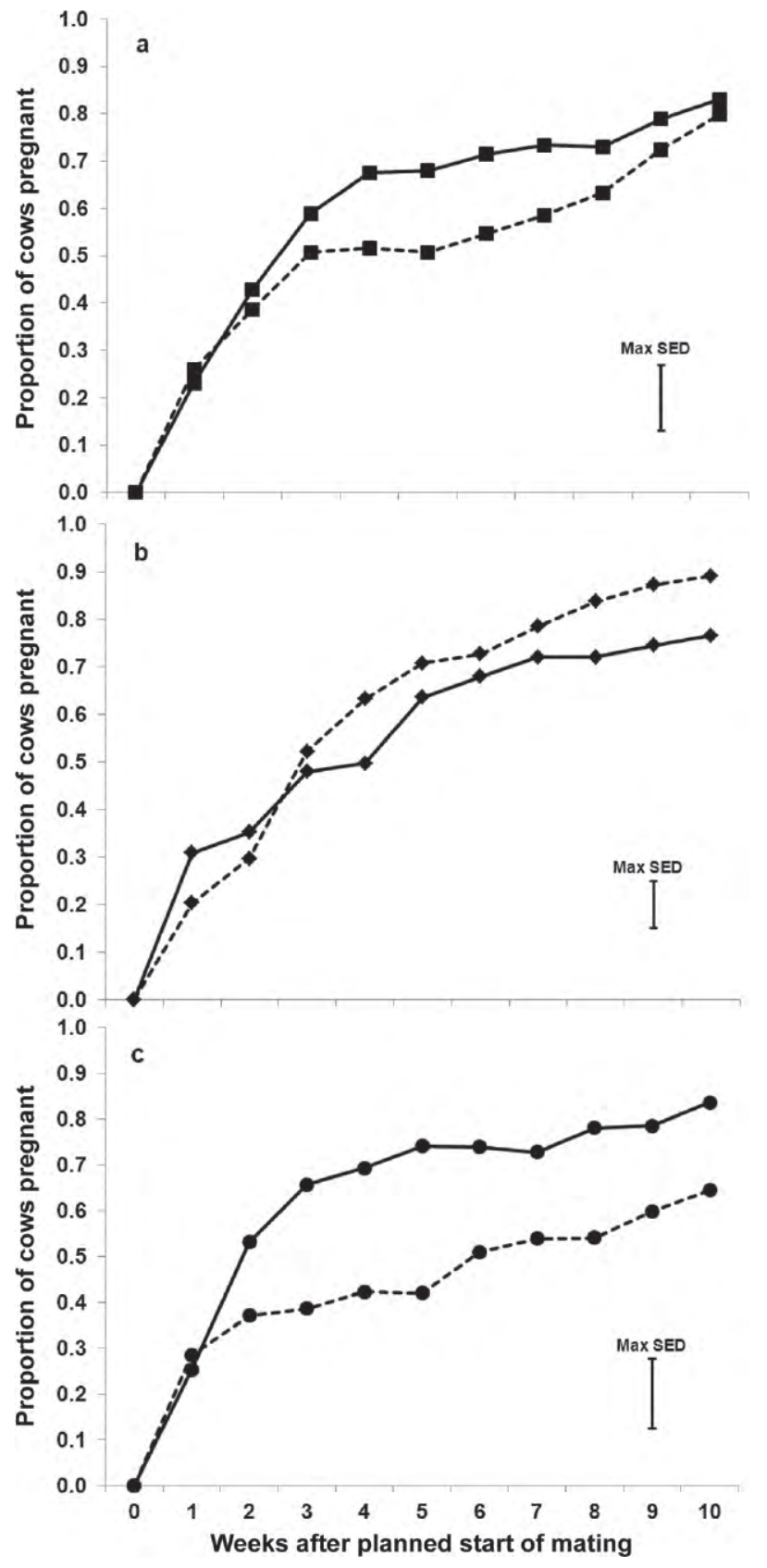

Figure 3. Effect of a nonsteroidal antiinflammatory drug (NSAID) treatment, and the interaction with (a) low- (ם, --- control, NSAID), (b) medium- (Med; - ,-- control, - NSAID), and (c) high(๑, --- control, - NSAID) polymorphonuclear cell (PMN) groups on the proportion of cows pregnant by a specified day after the planned start of mating. Uterine cytology results from samples collected on $\mathrm{d}$ 14 postpartum were used to retrospectively create 3 PMN groups: low PMN ( $\leq 1 \%$ PMN), medium PMN (2 to $13 \%$ PMN), and high PMN $(\geq 14 \%$ PMN). The weekly pregnancy proportions were calculated using the estimated conception date, which was calculated using the final pregnancy test results and mating data. An interaction $(P=$ 0.04 ) existed between NSAID treatment and PMN group 4 wk after the planned start of mating and a trend for an interaction existed at wk $5(P=0.06), 8(P=0.07), 9$ and $10(P=0.09)$; the interaction reflects an increase in pregnancy rate in the high-PMN group treated with NSAID, but not in the low- or medium-PMN groups. Max SED $=$ maximum standard error of the difference. tion in high-PMN cows. To support this hypothesis, high-yielding, TMR-fed cows treated with aspirin (an NSAID) during the first $5 \mathrm{~d}$ postpartum in the Trevisi and Bertoni (2008) study had higher milk production and improved reproductive performance compared with untreated cows. An earlier timing of NSAID treatment (i.e., from calving) in pasture-grazing cows may, therefore, be worthy of future investigation.

\section{Associations Between PMN Percentage and Reproduction, Metabolic Indicators, and Milk Production}

The cutoff point of $\geq 14 \%$ PMN as the definition of SCE in the current study was based on the lowest value of the upper quartile. The advantage in using this approach is that the numbers of animals assigned to PMN groups (low, medium, and high) are balanced for statistical power: the same approach used by Burke et al. (2010). The limitation, however, is that the cutoff point is established by the distribution of PMN percentage values within the experimental population, and not by a predefined level that is necessarily validated as having a significant biological effect. It is, therefore, possible that SCE as defined in this study is of a less severe condition compared with similarly classified animals in other reports (Kasimanickam et al., 2004; Barlund et al., 2008; Dubuc et al., 2010). This fact may have limited the ability to detect an effect of the NSAID treatment and any interactions between PMN group and treatment. However, some significant biological differences existed relating to the high-PMN group: a trend for a lower proportion of cows ovulated by d 28 postpartum; lower plasma concentrations of albumin and Ca; lower albumin:globulin ratio; elevated concentrations of ASAT, GDH, and NEFA; and highPMN cows were thinner than cows in the other 2 PMN categories. The indications are that the cutoff point used in this study is biologically relevant.

The associations between PMN group and reproduction and indicators of metabolic/inflammatory challenge found in the current study are generally consistent with previous reports in pasture-fed dairy cows (Burke et al., 2010; McDougall et al., 2011). These associations indicate physiological dysfunction, including lower body condition, liver dysfunction, and greater metabolic challenge during the periparturient period among cows with elevated PMN percentages in the uterus postpartum.

The negative association between PMN group and albumin concentrations and the albumin:globulin ratio is similar to that reported previously (Green et al., 2009; Burke et al., 2010). Albumin is a liver-derived negative acute-phase protein (Fleck, 1989) and is com- 

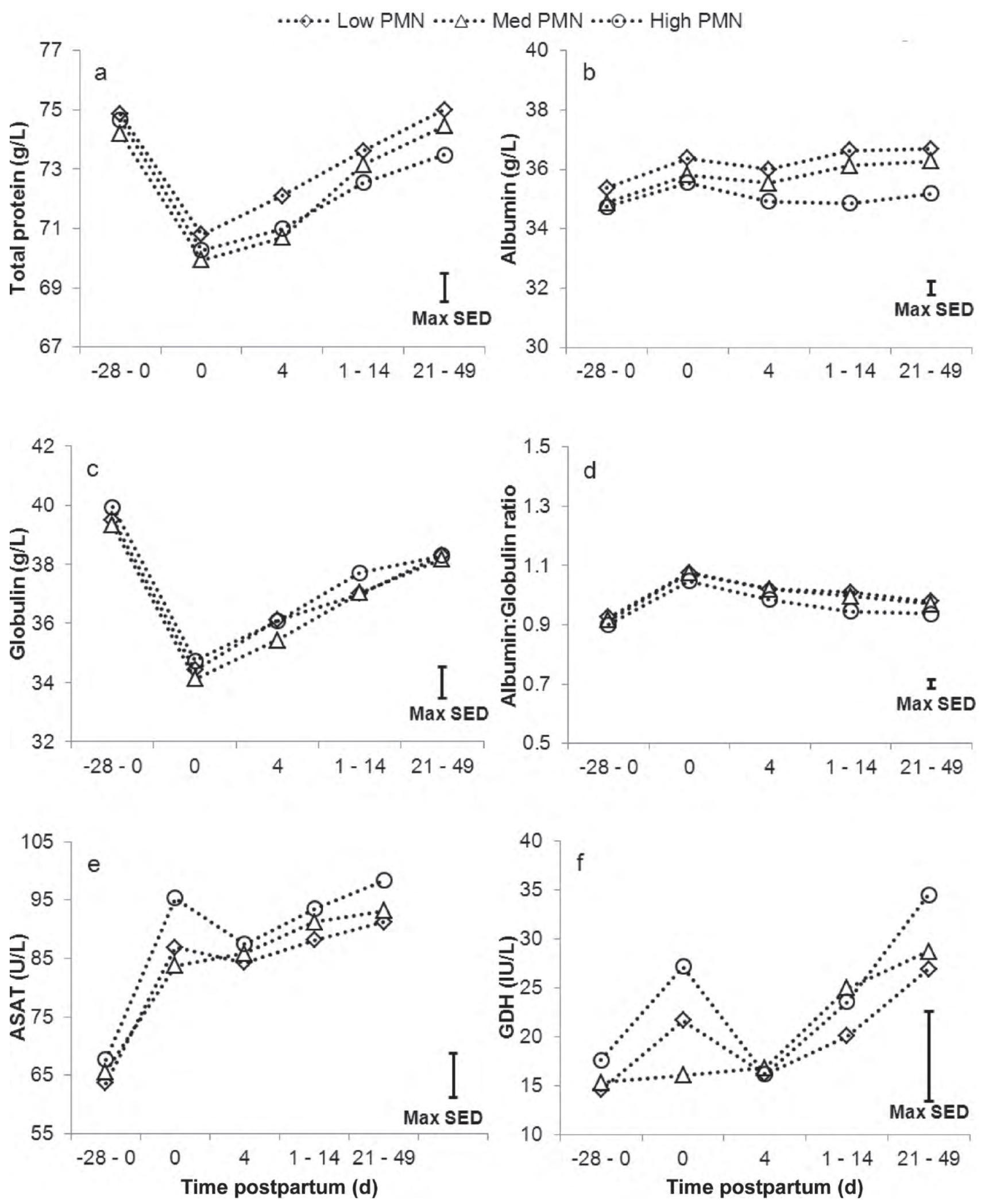

Figure 4. Plasma concentrations of (a) total protein, (b) albumin, (c) globulin, (d) the albumin:globulin ratio, (e) aspartate aminotransferase (ASAT), and (f) glutamate dehydrogenase (GDH) for the polymorphonuclear cell (PMN) groups based on uterine cytology results from samples collected on d 14 postpartum: low PMN ( $\leq 1 \%$ PMN), medium (Med) PMN (2 to $13 \%$ PMN), and high PMN ( $\geq 14 \%$ PMN). Raw means and the maximum standard error of the difference (Max SED) are presented. 
monly regarded as a marker of impaired liver function (Bertoni et al., 2008). Together with a tendency for plasma concentrations of ASAT and GDH to be higher in the high-PMN cows, the indications are that liver dysfunction is a characteristic of cows with elevated PMN percentage.

Cows in the high-PMN group were thinner than cows in the other PMN categories pre- and postpartum and had higher plasma NEFA concentrations on the day of calving. Low precalving BCS has previously been reported as a risk factor for SCE in pasture-grazed cows (McDougall et al., 2011), and increased body fat mobilization, as evidenced by elevated NEFA concentrations, was associated with lower DMI and an increased risk of metritis (Hammon et al., 2006; Duffield et al., 2009). Furthermore, the high-PMN group had a lower plasma concentration of $\mathrm{Ca}$ on the day of calving, a key time that can reveal the extent of hypocalcaemia experienced by a dairy herd (Goff, 2008). Low Ca during the transition period reduces immune function and is a risk factor for endometritis in TMR-fed dairy cows (Mateus and da Costa, 2002; Kimura et al., 2006). Additionally, cows with reduced liver function have lower plasma Ca concentrations compared with unaffected cows (Bertoni et al., 2008). Further studies are required to better understand the underlying reasons for the links between SCE and indicators of physiological dysfunction in SCE cows precalving.

This study found no statistically significant differences in milk yield between the PMN groups, which is consistent with the results reported by Dubuc et al. (2011), but is not consistent with other studies in both pasture-grazed and TMR-based systems that have reported a negative association between PMN percentage and milk yield (Senosy et al., 2009; Burke et al., 2010; McDougall et al., 2011). The $0.9 \mathrm{~kg} / \mathrm{d}$ reduction in milk yield for the high-PMN cows reported in the current study is similar to the 1 and $0.6 \mathrm{~kg} / \mathrm{d}$ reduction in milk yield reported by McDougall et al. (2011) and Burke et al. (2010), respectively, indicating that a degree of caution is required with this statistical interpretation.

\section{CONCLUSIONS}

Although NSAID treatment did not affect uterine PMN percentage at d 42 postpartum or milk production, treatment increased pregnancy rates in high-PMN cows and improved liver functionality in all cows. Results confirm the earlier findings that cows with SCE present a degree of physiological dysfunction during the periparturient period, with particular evidence for liver dysfunction. Further studies need to be conducted to elucidate the causes of the precalving physiological dysfunction associated with SCE and to evaluate the effect
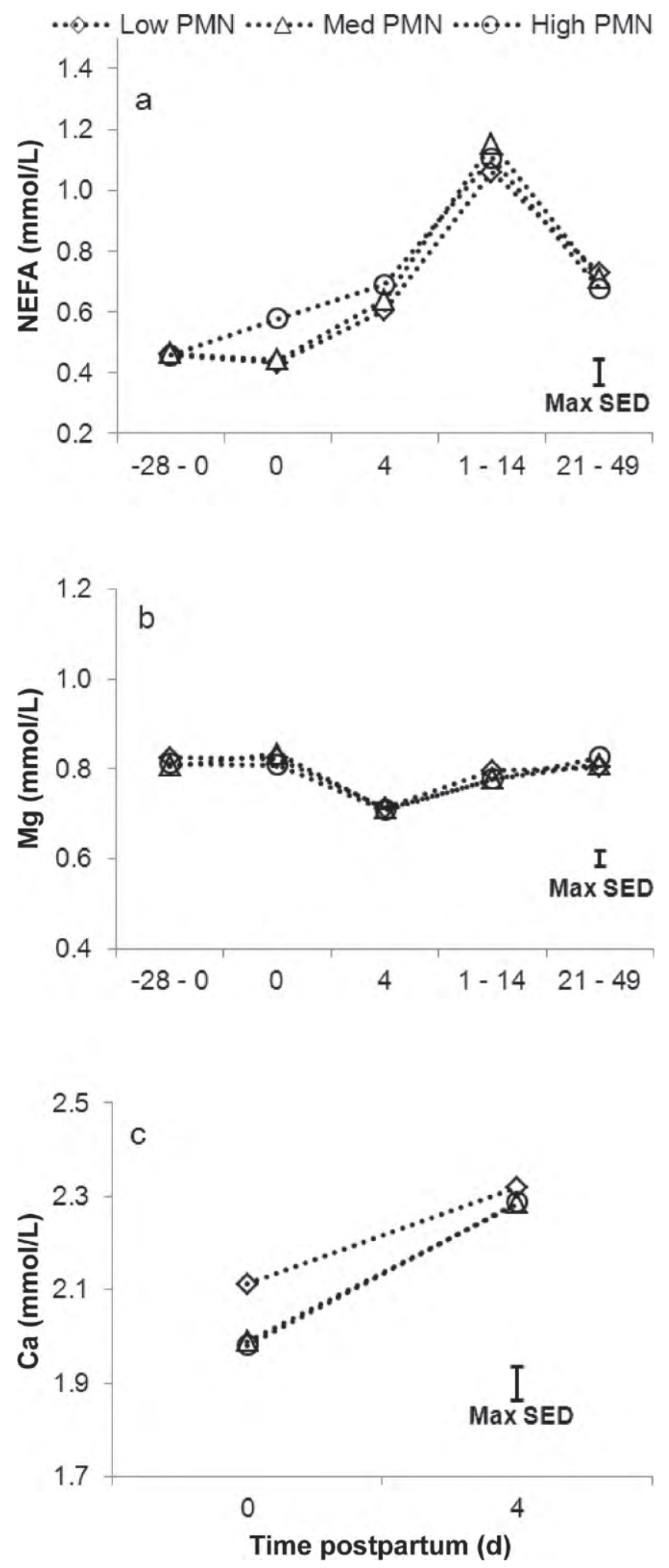

Figure 5. Plasma concentrations of (a) NEFA, (b) Mg, and (c) $\mathrm{Ca}$ for the polymorphonuclear cell (PMN) groups based on uterine cytology results from samples collected on d 14 postpartum: low PMN $(\leq 1 \%$ PMN), medium (Med) PMN (2 to $13 \%$ PMN), and high PMN $(\geq 14 \% \mathrm{PMN})$. Raw means and the maximum standard error of the difference (Max SED) are presented. 
of timing of NSAID treatment on milk production and reproduction variables.

\section{ACKNOWLEDGMENTS}

The authors thank the DairyNZ Scott Farm (Hamilton, New Zealand) staff and technicians for their assistance with data collection, Barbara Dow (Dairy NZ, Hamilton, New Zealand) for statistical analysis assistance, and Kelly Buckle [Institute of Veterinary, Animal and Biomedical Sciences (IVABS), Massey University, Palmerston North, New Zealand] for cytology microscopy. This research was funded by New Zealand dairy farmers through DairyNZ Inc. (AN808) and the Ministry of Business, Innovation and Employment (Wellington, New Zealand; UOAX0814).

\section{REFERENCES}

Barański, W., M. Podhalicz-Dzięgielewska, S. Zduńczyk, and T. Janowski. 2012. The diagnosis and prevalence of subclinical endometritis in cows evaluated by different cytologic thresholds. Theriogenology 78:1939-1947.

Barlund, C. S., T. D. Carruthers, C. L. Waldner, and C. W. Palmer. 2008. A comparison of diagnostic techniques for postpartum endometritis in dairy cattle. Theriogenology 69:714-723.

Battaglia, D. F., A. B. Beaver, T. G. Harris, E. Tanhehco, C. Viguie, and F. J. Karsch. 1999. Endotoxin disrupts the estradiol-induced luteinizing hormone surge: Interference with estradiol signal reading, not surge release. Endocrinology 140:2471-2479.

Bertoni, G., E. Trevisi, X. Han, and M. Bionaz. 2008. Effects of inflammatory conditions on liver activity in puerperium period and consequences for performance in dairy cows. J. Dairy Sci. 91:3300-3310.

Burke, C. R., S. Meier, S. McDougall, C. Compton, M. Mitchell, and J. R. Roche. 2010. Relationships between endometritis and metabolic state during the transition period in pasture-grazed dairy cows. J. Dairy Sci. 93:5363-5373.

Dubuc, J., T. F. Duffield, K. E. Leslie, J. S. Walton, and S. J. LeBlanc. 2010. Definitions and diagnosis of postpartum endometritis in dairy cows. J. Dairy Sci. 93:5225-5233.

Dubuc, J., T. F. Duffield, K. E. Leslie, J. S. Walton, and S. J. Leblanc. 2011. Effects of postpartum uterine diseases on milk production and culling in dairy cows. J. Dairy Sci. 94:1339-1346.

Duffield, T. F., K. D. Lissemore, B. W. McBride, and K. E. Leslie. 2009. Impact of hyperketonemia in early lactation dairy cows on health and production. J. Dairy Sci. 92:571-580.

Erdem, H., and A. Guzeloglu. 2010. Effect of meloxicam treatment during early pregnancy in Holstein heifers. Reprod. Domest. Anim. 45:625-628.

Fleck, A. 1989. Clinical and nutritional aspects of changes in acutephase proteins during inflammation. Proc. Nutr. Soc. 48:347-354.

Galvão, K. N., M. Frajblat, S. B. Brittin, W. R. Butler, C. L. Guard, and R. O. Gilbert. 2009a. Effect of prostaglandin $\mathrm{F}_{2 \alpha}$ on subclinical endometritis and fertility in dairy cows. J. Dairy Sci. 92:49064913.

Galvão, K. N., L. F. Greco, J. M. Vilela, M. F. Sá Filho, and J. E. Santos. 2009b. Effect of intrauterine infusion of ceftiofur on uterine health and fertility in dairy cows. J. Dairy Sci. 92:1532-1542.

Gilbert, R. O., S. T. Shin, C. L. Guard, H. N. Erb, and M. Frajblat. 2005. Prevalence of endometritis and its effects on reproductive performance of dairy cows. Theriogenology 64:1879-1888.

Goff, J. P. 2008. The monitoring, prevention, and treatment of milk fever and subclinical hypocalcemia in dairy cows. Vet. J. 176:50-57.
Green, M. P., A. M. Ledgard, M. C. Berg, A. J. Peterson, and P. J. Back. 2009. Prevalence and identification of systemic markers of sub-clinical endometritis in postpartum dairy cows. Proc. N.Z. Soc. Anim. Prod. 69:37-42.

Hammon, D. S., I. M. Evjen, T. R. Dhiman, J. P. Goff, and J. L. Walters. 2006. Neutrophil function and energy status in Holstein cows with uterine health disorders. Vet. Immunol. Immunopathol. 113:21-29.

Herath, S., E. J. Williams, S. T. Lilly, R. O. Gilbert, H. Dobson, C. E Bryant, and I. M. Sheldon. 2007. Ovarian follicular cells have innate immune capabilities that modulate their endocrine function. Reproduction 134:683-693.

Heuwieser, W., M. Iwersen, and L. Goetze. 2011. Efficacy of carprofen on conception rates in lactating dairy cows after subcutaneous or intrauterine administration at the time of breeding. J. Dairy Sci. 94:146-151.

Kasimanickam, R., T. F. Duffield, R. A. Foster, C. J. Gartley, K. E. Leslie, J. S. Walton, and W. H. Johnson. 2004. Endometrial cytology and ultrasonography for the detection of subclinical endometritis in postpartum dairy cows. Theriogenology 62:9-23.

Kasimanickam, R., T. F. Duffield, R. A. Foster, C. J. Gartley, K. E. Leslie, J. S. Walton, and W. H. Johnson. 2005. The effect of a single administration of cephapirin or cloprostenol on the reproductive performance of dairy cows with subclinical endometritis. Theriogenology 63:818-830.

Kimura, K., T. A. Reinhardt, and J. P. Goff. 2006. Parturition and hypocalcemia blunts calcium signals in immune cells of dairy cattle. J. Dairy Sci. 89:2588-2595.

Ludwig, B., J. C. Jordan, W. F. Rehm, and R. Thun. 1989. Carprofen in veterinary medicine. I. Plasma disposition, milk excretion and tolerance in milk-producing cows. Schweiz. Arch. Tierheilkd. 131:99-106.

Mateus, L., and L. L. da Costa. 2002. Peripartum blood concentrations of calcium, phosphorus and magnesium in dairy cows with normal puerperium or puerperal endometritis. Revista Portuguesa de Ciências Veterinárias 97:35-38.

McDougall, S., H. Hussein, D. Aberdein, K. Buckle, J. Roche, C. Burke, M. Mitchell, and S. Meier. 2011. Relationships between cytology, bacteriology and vaginal discharge scores and reproductive performance in dairy cattle. Theriogenology 76:229-240.

McDougall, S., R. Macaulay, and C. Compton. 2007. Association between endometritis diagnosis using a novel intravaginal device and reproductive performance in dairy cattle. Anim. Reprod. Sci. 99:9-23.

Norbrook Laboratories. 2011. Carprieve $50 \mathrm{mg} / \mathrm{ml}$ solution for injection for cattle. Vol. 2011. Norbrook New Zealand Ltd., Auckland, New Zealand.

Rhodes, F. M., S. McDougall, C. R. Burke, G. A. Verkerk, and K. L. Macmillan. 2003. Invited review: Treatment of cows with an extended postpartum anestrous interval. J. Dairy Sci. 86:1876-1894.

Roche, J. R., P. G. Dillon, C. R. Stockdale, L. H. Baumgard, and M. J. VanBaale. 2004. Relationships among international body condition scoring systems. J. Dairy Sci. 87:3076-3079.

Senosy, W. S., M. Uchiza, N. Tameoka, Y. Izaike, and T. Osawa. 2009. Association between evaluation of the reproductive tract by various diagnostic tests and restoration of ovarian cyclicity in highproducing dairy cows. Theriogenology 72:1153-1162.

Sheldon, I. M., J. Cronin, L. Goetze, G. Donofrio, and H.-J. Schuberth. 2009. Defining postpartum uterine disease and the mechanisms of infection and immunity in the female reproductive tract in cattle. Biol. Reprod. 81:1025-1032.

Sordillo, L. M., G. A. Contreras, and S. L. Aitken. 2009. Metabolic factors affecting the inflammatory response of periparturient dairy cows. Anim. Health Res. Rev. 10:53-63.

Trevisi, E., and G. Bertoni. 2008. Attenuation of acetylsalicylate treatments of inflammatory conditions in periparturient dairy cows. Pages 22-37 in Aspirin and Health Research Progress. Nova Science Publishers, New York, NY.

VSN International Ltd. 2011. GenStat for Windows. 14th ed. VSN International Ltd., Hemel Hempstead, UK. 